\title{
BCL2/Ki-67 index predict survival in germinal center B-cell-like diffuse large B-cell lymphoma
}

\author{
YUN-LONG TANG $^{1 *}$, YAN ZHOU $^{1 *}$, LING-LING CHENG $^{2}$, YONG-ZHONG SU $^{3}$ and CHUN-BIN WANG ${ }^{1}$ \\ ${ }^{1}$ Department of Hematology and Oncology, The Affiliated Hospital of Southeast University, \\ The Third People's Hospital of Yancheng; ${ }^{2}$ Department of Oncology, Yancheng Hospital of Traditional \\ Chinese Medicine, Yancheng, Jiangsu 224000; ${ }^{3}$ Department of Hematology, The First Affiliated \\ Hospital of Shantou University Medical College, Shantou, Guangdong 515000, P.R. China
}

Received January 5, 2017; Accepted June 14, 2017

DOI: $10.3892 / \mathrm{ol} .2017 .6577$

\begin{abstract}
Diffuse large B-cell lymphoma (DLBCL) is the most common type of non-Hodgkin lymphoma. BCL2 apoptosis regulator (BCL2) and marker of proliferation $\mathrm{Ki}-67$ (Ki-67) are established prognostic markers, which have traditionally been assessed separately in DLBCL. However, no studies have evaluated the prognostic value of the combination of BCL2 and Ki-67 index. Thus, the present study aimed to analyze the prognostic value of combination of these two markers. Immunohistochemical analysis was used to assess the expression of BCL2 and Ki-67 in 274 cases of DLBCL. The BCL2/Ki-67 index demonstrated a significant association with decreased overall and progression free survival of patients with DLBCL, particularly for the germinal center B-cell-like subtype of DLBCL. Following multivariate analysis, the BCL2/Ki-67 index retained prognostic significance. Patients with coexpression of BCL2 and Ki-67 constituted a unique group with poor survival, thus novel therapies targeting BCL2 protein and high proliferative activity may improve the outcome of these patients.
\end{abstract}

\section{Introduction}

Diffuse large B-cell lymphoma (DLBCL) is the most common subtype of non-Hodgkin lymphoma (NHL), accounting for $30-40 \%$ of all NHL patients (1-3), which is considered to be a heterogeneous entity based on its biological characteristics and clinical outcomes (3-5). The survivals of DLBCL patients have notably improved since addition of rituximab to $\mathrm{CHOP}$

Correspondence to: Dr Chun-Bin Wang, Department of Hematology and Oncology, The Affiliated Hospital of Southeast University, The Third People's Hospital of Yancheng, 75 Ju Chang Road, Yancheng, Jiangsu 224000, P.R. China

E-mail: interboy1314@163.com

*Contributed equally

Key words: BCL2, Ki-67, prognosis, diffuse large B-cell lymphoma (rituximab, cyclophosphamide, doxorubicin, vincristine, and prednisone) chemotherapy $(6,7)$. However, some DLBCL patients continue to present an inferior prognosis under standard R-CHOP therapy (1).

$\mathrm{Ki}-67$, a nuclear nonhistone protein, is synthesized at the beginning of cell proliferation (8). Ki-67 expression has been widely used in clinical practice as an index to evaluate the proliferative activity of lymphoma. High Ki-67 expression was highly associated with worse OS for NHL (9). However, the relationship between $\mathrm{Ki}-67$ expression and outcome with DLBCL are still contradictory and inconclusive in various studies (10-12).

BCL2 protein functions as an antiapoptotic protein inhibiting cells from programmed cell death (13). Both gene amplification and translocation are common mechanisms causing BCL2 protein overexpression in DLBCL. The clinical significance of BCL2 protein expression in DLBCL is still controversial. The impact of BCL2 overexpression on survival in DLBCL is still debatable in previous studies. Additionally, the prognostic value of BCL2 protein overexpression is also different between GCB and ABC subtypes $(14,15)$.

Moreover, the predictive significance of some prognostic factors changed following the introduction of a CD20 monoclonal antibody, rituximab, underscores the necessity for revaluating the prognostic value of predictive factors after the introduction of rituximab $(7,16)$.

In the present study, we intended to investigate the optimal prognosis cut off value of $\mathrm{Ki}-67$ index in DLBCL patients, and to confirm the specific prognostic value of BCL2 and its association with cell of origin classification (COOC). Furthermore, we investigated whether the BCL2/Ki-67 index has a more significant importance on the outcome of DLBCL patients.

\section{Materials and methods}

Patient selection. Between August 2003 and January 2016, 274 patients with de novo DLBCL were enrolled in the present study. Patients of special types of DLBCL were excluded from this study. All patients enrolled informed consent in accordance with requirements of the Declaration of Helsinki, and the research project was approved by the University and Institutional Review Boards. Formalin-fixed, paraffin embedded 
(FFPE) tissue biopsy specimens were available for all patients. All atients were treated with R-CHOP like therapies.

Immunohistochemistry (IHC). IHC was performed on FFPE sections. The antibodies used were CD10 (clone 56C6; Invitrogen Life Technologies, Carlsbad, CA, USA), BCL6 (clone PG-B6P; Dako, Carpinteria, CA, USA), MUM1 (clone MUM1p, Dako), KI-67 (clone SP6, Abcam, Cambridge, UK) and BCL2 (clone 124; Dako). The staining results were showed in Fig. 1. COOC was performed by immunohistochemical stains using the Hans criteria (17). Immunostains for CD10, BCL6, and MUM1 were used to classify cases as having germinal center B-cell (GCB)-like or non-germinal center B-cell (NGC)-like immunophenotype. The cut off scores for each antibody were described previously $(17,18)$. $\mathrm{BK}^{+}$was defined as BCL2 positive and high $\mathrm{Ki}-67$ proliferation $(\geq 90 \%)$. $\mathrm{BK}^{+}$was defined as BCL2 negative and low Ki-67 proliferation $(<90 \%)$.

Statistical analysis. Overall survival (OS) and progression-free survival (PFS) were the primary end points of this study. OS was calculated from the date of diagnosis to the date of death due to any cause or to the date of the last follow up. PFS was calculated from the date of first progression, relapse, death, or the last follow-up. Patients who were alive and progression-free at last follow-up were censored for this analysis. Statistical analysis was carried out with SPSS 16.0 software. Survival curves were plotted by using Kaplan-Meier method and were compared by using log-rank test. Differences were determined using a two-tailed log-rank test, and $\mathrm{P}<0.05$ was considered to indicate a statistically significant difference.

\section{Results}

Patient characteristics patient. Clinic-pathologic characteristics were presented in Table I. We examined BCL2 and Ki-67 protein expression by IHC in the R-CHOP-like cohort including GCB-DLBCL (52/126, 41.3\%), NGC-DLBCL (86/148, 58.1\%). We detected Ki-67 proliferation index in GCB-DLBCL and NGC-DLBCL (Table I).

Prognosis of BCL2 protein. Based on the data published previously, we selected a cut off of $\geq 70 \%$ protein expression for BCL2 positivity. In the total cohort, the BCL2 positive rate was $50.4 \%$ (138/274). The BCL2 positive patients show a significantly shorter OS $(\mathrm{P}=0.022)$ and $\mathrm{PFS}(\mathrm{P}<0.001)$ compared with the BCL2 negative cases (Fig. 2A and B). We further analyzed BCL2 prognostic value according to different COOC. In GCB group, BCL2 positivity predict poorer outcome than negative ones (OS: $\mathrm{P}=0.007$; PFS: $\mathrm{P}=0.0002$ ) (Fig. $2 \mathrm{C}$ and D). However, in the NGC group, BCL2 positive patients had a similar OS (OS: $\mathrm{P}=0.391$ ) and PFS (PFS: $\mathrm{P}=0.159)$ with negative ones (Fig. 2E and F). Multivariate analysis by Cox proportional hazards regression, BCL2 positivity remains independent prognostic factor on PFS ( $\mathrm{P}=0.006)$ (Tables II and III).

Prognosis of proliferation index. We then analyzed the prognostic value of the Ki-67 index, the incidence of Ki-67 proliferation by different cut offs were illustrated in Table I. In the total cohort, the $\mathrm{Ki}-67$ index only showed shorter PFS $(\mathrm{P}=0.002)$ but not OS $(\mathrm{P}=0.085)$ by the cut off of $90 \%$
Table I. Clinical and immunohistochemical characteristics of DLBCL patients.

\begin{tabular}{lr} 
Variables & Number of cases \\
\hline Age $\geq 60$ y & $118(43.1)$ \\
Male & $180(65.7)$ \\
Stage III-IV & $146(52.3)$ \\
Abnormal LDH level & $114(41.6)$ \\
Performance state 2-4 & $54(19.7)$ \\
Extranodal involvement $\geq 2$ & $64(23.4)$ \\
B symptom & $102(37.2)$ \\
IPI $\geq 4$ & $26(9.5)$ \\
GCB & $126(46.0)$ \\
Non-GCB & $148(54.0)$ \\
BCL2 positive & $138(50.4)$ \\
Ki-67 $\geq 60 \%$ & $210(76.6)$ \\
Ki-67 $\geq 70 \%$ & $180(65.7)$ \\
Ki-67 $\geq 80 \%$ & $122(44.5)$ \\
Ki-67 $\geq 90 \%$ & $58(21.2)$
\end{tabular}

LDH, lactic dehydrogenase; GCB, germinal center B-cell; IPI, international prognostic index.

(Fig. 3A, B), none of the other cut offs showed a different outcome with both OS and PFS (data not show). In the GCB group, the $\mathrm{Ki}-67$ index predicted both poorer OS $(\mathrm{P}<0.001)$ and PFS $(\mathrm{P}<0.001)$ by the cu toff of $90 \%$ alone (Fig. 3C, D). In the NGC group, only the cut off of $70 \%$ showed a shorter PFS $(\mathrm{P}=0.024)$ but not OS $(\mathrm{P}=0.150)$ (Fig. 3E, F).

The prognostic value of the BCL2/Ki-67 index. Since the Ki-67 index showed a better prognosis value with the cut off of $90 \%$, we then analyzed the prognosis of group with BCL2 positivity and high $\mathrm{Ki}-67$ proliferation $(\geq 90 \%)\left(\mathrm{BK}^{+}\right)$. In the total cohort, $\mathrm{BK}^{+}$ patients showed a similar OS $(\mathrm{P}=0.142)$ and $\mathrm{PFS}(\mathrm{P}=0.062)$ with the rest cases (single positive or double negative) (Fig. 4A and $\mathrm{B}$ ) or single BCL2 positivity (OS: $\mathrm{P}=0.541$, $\mathrm{PFS}$ : $\mathrm{P}=0.606$ ) or high Ki-67 (OS: $\mathrm{P}=0.128$, PFS: $\mathrm{P}=0.299)$. However, $\mathrm{BK}^{+}$showed significantly shorter OS $(\mathrm{P}=0.004)$ and $\mathrm{PFS}(\mathrm{P}<0.001)$ than double negative ones (BK) (Fig. 4C and D). In the GCB group, just like the total group, $\mathrm{BK}^{+}$patients had similar $\mathrm{OS}(\mathrm{P}=0.265)$ and PFS ( $\mathrm{P}=0.315)$ with the rest cases (Fig. $5 \mathrm{~A}$ and $\mathrm{B}$ ) or single BCL2 positivity (OS: $\mathrm{P}=0.810$, PFS: $\mathrm{P}=0.943$ ) or high Ki-67 (OS: $\mathrm{P}=0.353$, PFS: $\mathrm{P}=0.135)$, but showed significantly poorer OS $(\mathrm{P}=0.005)$ and PFS $(\mathrm{P}<0.001)$ than $\mathrm{BK}$-ones (Fig. 5C and D). In the $\mathrm{NGC}$ group, however, $\mathrm{BK}^{+}$showed similar outcome with either $\mathrm{BK}^{-}(\mathrm{OS}: \mathrm{P}=0.269$; $\mathrm{PFS}$ : $\mathrm{P}=0.125)$ (Fig. $6 \mathrm{~A}$ and $\left.\mathrm{B}\right)$ or the rest (OS: $\mathrm{P}=0.438$; $\mathrm{PFS}$ : $\mathrm{P}=0.207$ ) (Fig. $6 \mathrm{C}$ and $\mathrm{D}$ ) or single BCL2 positivity (OS: $\mathrm{P}=0.549$, $\mathrm{PFS}: \mathrm{P}=0.394)$ or high Ki-67 (OS: $\mathrm{P}=0.502$, PFS: $\mathrm{P}=0.823$ ). Multivariate analysis by Cox proportional hazards regression, accounting for BCL2 and $\mathrm{Ki}-67$ index, demonstrated that the poor prognostic effect of $\mathrm{BK}^{+}$remained significant after adjusting for the presence of the additional high risk features of extranodal involvement $\geq 2$, Elevated LDH level, Stage III and IV, high IPI risk, B symptom and poor performance state $(\mathrm{P}=0.026)$ (Tables II and III). 

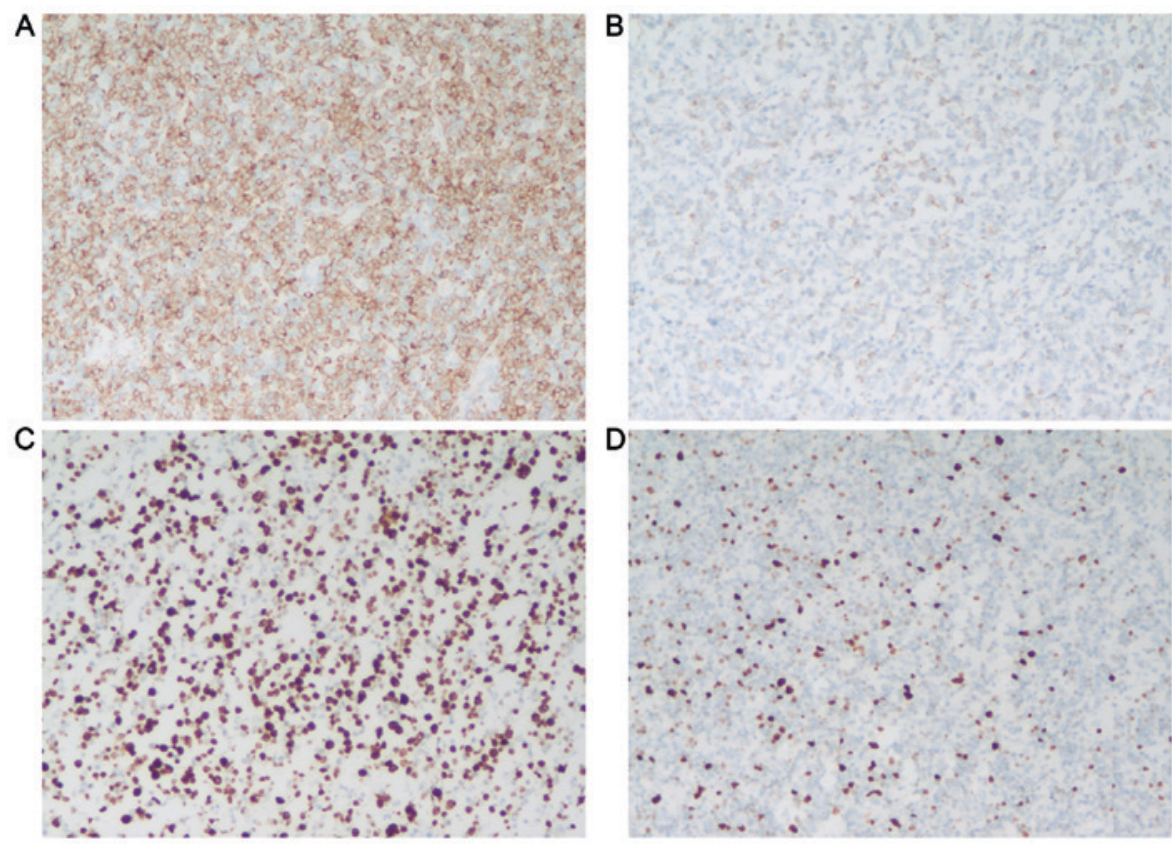

Figure 1. Immunohistochemical analysis of BCL2 and Ki-67 protein expression in DLBCL. (A) BCL2 protein positive; (B) BCL2 protein negative; (C) High Ki-67 expression; (D) Low Ki-67 expression. DLBCL, diffuse large B-cell lymphoma.
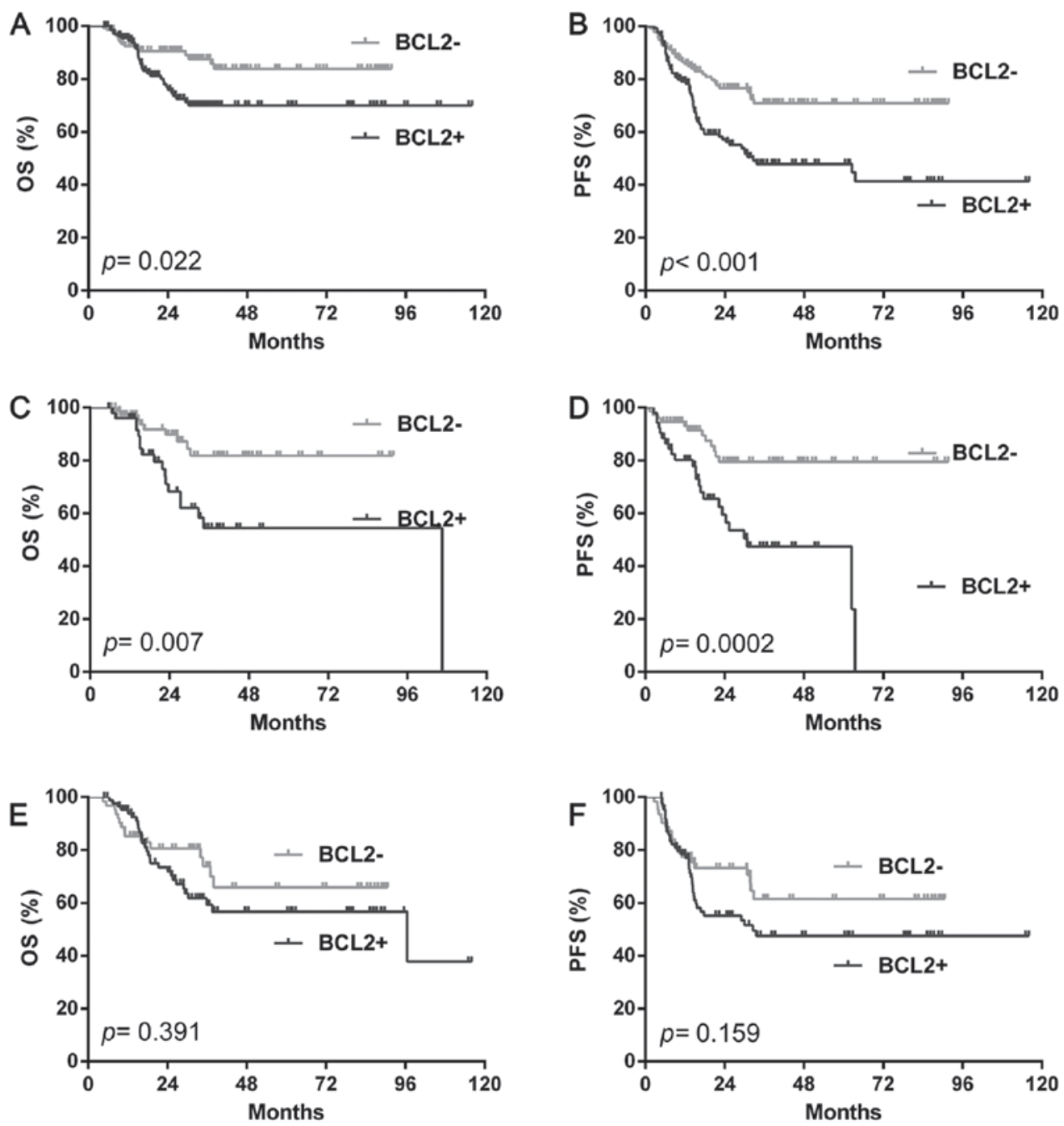

Figure 2. OS and PFS of patients with DLBCL of the BCL2 protein expression. (A) OS and (B) PFS with BCL2 positive and negative patients in total cohort. (C) OS and (D) PFS with BCL2 positive and negative patients in GCB-DLBCL cohort. (E) OS and (F) PFS with BCL2 positive and negative patients in NGC-DLBCL cohort. OS, overall survival; PFS, progression-free survival; DLBCL, diffuse large B-cell lymphoma; GCB, germinal center B-cell. 
Table II. Univariate and multivariate analysis with OS.

\begin{tabular}{lcccccr}
\hline Variables & HR & $95 \% \mathrm{CI}$ & P-value & HR & $95 \%$ CI & P-value \\
\hline Extranodal involvement $\geq 2$ & 2.393 & $1.679-5.326$ & 0.0002 & 0.433 & $0.173-1.084$ & 0.074 \\
Elevated LDH level & 2.317 & $1.508-3.923$ & 0.0003 & 0.825 & $0.300-2.266$ & 0.709 \\
Stage III-IV & 1.700 & $1.060-2.693$ & 0.030 & 1.498 & $0.546-4.109$ & 0.432 \\
IPI $\geq 4$ & 3.422 & $3.192-22.14$ & $<0.0001$ & 1.141 & $0.250-5.216$ & 0.865 \\
B symptom & 1.673 & $1.066-2.819$ & 0.0275 & 1.067 & $0.401-2.836$ & 0.897 \\
Performance state 2-4 & 2.052 & $1.313-4.663$ & 0.0052 & 0.239 & $0.099-0.580$ & 0.002 \\
BCL2 $\geq 50 \%$ & 1.987 & $1.102-3.416$ & 0.022 & 0.621 & $0.368-1.049$ & $\mathbf{0 . 0 7 5}$ \\
Ki-67 $\geq 90 \%$ & 1.755 & $0.9153-4.290$ & 0.0850 & 0.679 & $0.372-1.241$ & 0.208 \\
BK $^{+}$ & 2.895 & $1.577-10.71$ & 0.0041 & 0.628 & $0.234-1.682$ & 0.354
\end{tabular}

LDH, lactic dehydrogenase; IPI, international prognostic index; BK, BCL2 and Ki-67 index; HR, hazard ratio; OS, overall survival.

Table III. Univariate and multivariate analysis with PFS.

\begin{tabular}{lcccccc}
\hline Variables & HR & $95 \% \mathrm{CI}$ & P-value & HR & $95 \% \mathrm{CI}$ & P-value \\
\hline Extranodal involvement $\geq 2$ & 2.094 & $1.493-4.122$ & 0.0016 & 1.494 & $0.754-2.962$ & 0.250 \\
Elevated LDH level & 2.140 & $1.484-3.434$ & 0.0002 & 0.461 & $0.274-0.775$ & 0.003 \\
Stage III-IV & 1.641 & $1.089-2.444$ & 0.018 & 0.572 & $0.337-0.971$ & 0.039 \\
IPI $\geq 4$ & 2.396 & $1.625-8.091$ & 0.0018 & 0.382 & $0.150-0.973$ & 0.044 \\
B symptom & 1.613 & $1.087-2.534$ & 0.0192 & 2.964 & $1.730-5.079$ & $<0.0001$ \\
Performance state 2-4 & 1.883 & $1.263-3.716$ & 0.0051 & 0.555 & $0.305-1.008$ & 0.053 \\
BCL2 $\geq 50 \%$ & 2.147 & $1.406-3.159$ & 0.0003 & 0.731 & $0.585-0.912$ & $\mathbf{0 . 0 0 6}$ \\
Ki-67 $\geq 90 \%$ & 1.978 & $1.363-4.083$ & 0.0024 & 0.673 & $0.406-1.116$ & 0.125 \\
BK $^{+}$ & 3.091 & $2.033-10.27$ & 0.0003 & 2.351 & $1.108-4.988$ & $\mathbf{0 . 0 2 6}$ \\
\hline
\end{tabular}

LDH, lactic dehydrogenase; IPI, international prognostic index; BK, BCL2 and Ki-67 index; HR, hazard ratio; PFS, progression-free survival.

\section{Discussion}

In the present study, we set out to evaluate the prognostic value of combining $\mathrm{Ki}-67$ and BCL2 as an index which would be superior to the evaluation of the markers separately.

$\mathrm{Ki}-67$ is an immunohistochemical marker of proliferating cells. Recent studies suggested that MYC and BCL2 protein co-expression is an independent indicator of poor prognosis in diffuse large B-cell lymphoma $(19,20)$. Since MYC positive DLBCL usually manifest a high proliferation rate, some research suggested the proliferation fraction criterion to $\geq 90 \%$ improved the specificity for detection $\mathrm{MYC}^{+}$double/triple translocations, which means $\mathrm{Ki}-67 \geq 90 \%$ might predict poor outcome (21). Therefore, further investigation is necessary to clearly delineate the relationship between $\mathrm{Ki}-67$ expression and prognosis in DLBCL. In our study, we confirmed the prognostic value of high Ki-67 index ( $\geq 90 \%)$ in GCB-DLBCL, which was in accordance with the prognosis of MYC gene rearrangement (22).

BCL2 is an anti-apoptotic protein which also has an antiproliferative effect influencing cell-cycle entry and is a powerful prognostic marker before rituximab. Studies showed that the addition of rituximab have eliminated the negative impact of the BCL2 expression $(23,24)$. However, the prognostic value of BCL2 protein in DLBCL was still controversial $(14,15)$. In our study, we showed BCL2 protein expression has a significant impact on OS and PFS in GCB-DLBCL, but not in NGC-DLBCL in the R-CHOP cohort, which was in accord with previous research (14).

Sustaining proliferative signaling and resisting cell death were two of the ten hallmarks of cancer, which play important role in cancer progression (25). In breast cancer, a BCL2/Ki-67 index based on IHC was highly prognostic in ER-positive patients. However, the prognostic value of BCL2/Ki-67 index has barely been investigated in DLBCL. With this purpose, we combined the high Ki-67 index ( $\geq 90 \%)$ and BCL2 positive patients together, named 'BK'. We showed $\mathrm{BK}^{+}$group had significantly poor outcome than $\mathrm{BK}^{-}$group. Stratification analysis showed GCB-DLBCL but not NGC-DLBCL retained the prognostic value of $\mathrm{BK}^{+}$. In multivariate analysis by $\mathrm{Cox}$ proportional hazards regression, $\mathrm{BK}^{+}$remained significantly prognostic factor of PFS in DLBCL. Since DLBCL is a heterogeneous entity, IHC test alone may not obtain the complete picture of this disease, hematologist need more effective indicators to tailor therapy. Nevertheless, the BCL2/Ki-67 index is a simple and convenient method to figure. out the patients' outcome of DLBCL, which would be a potential complement of current genetic heterogeneity. 

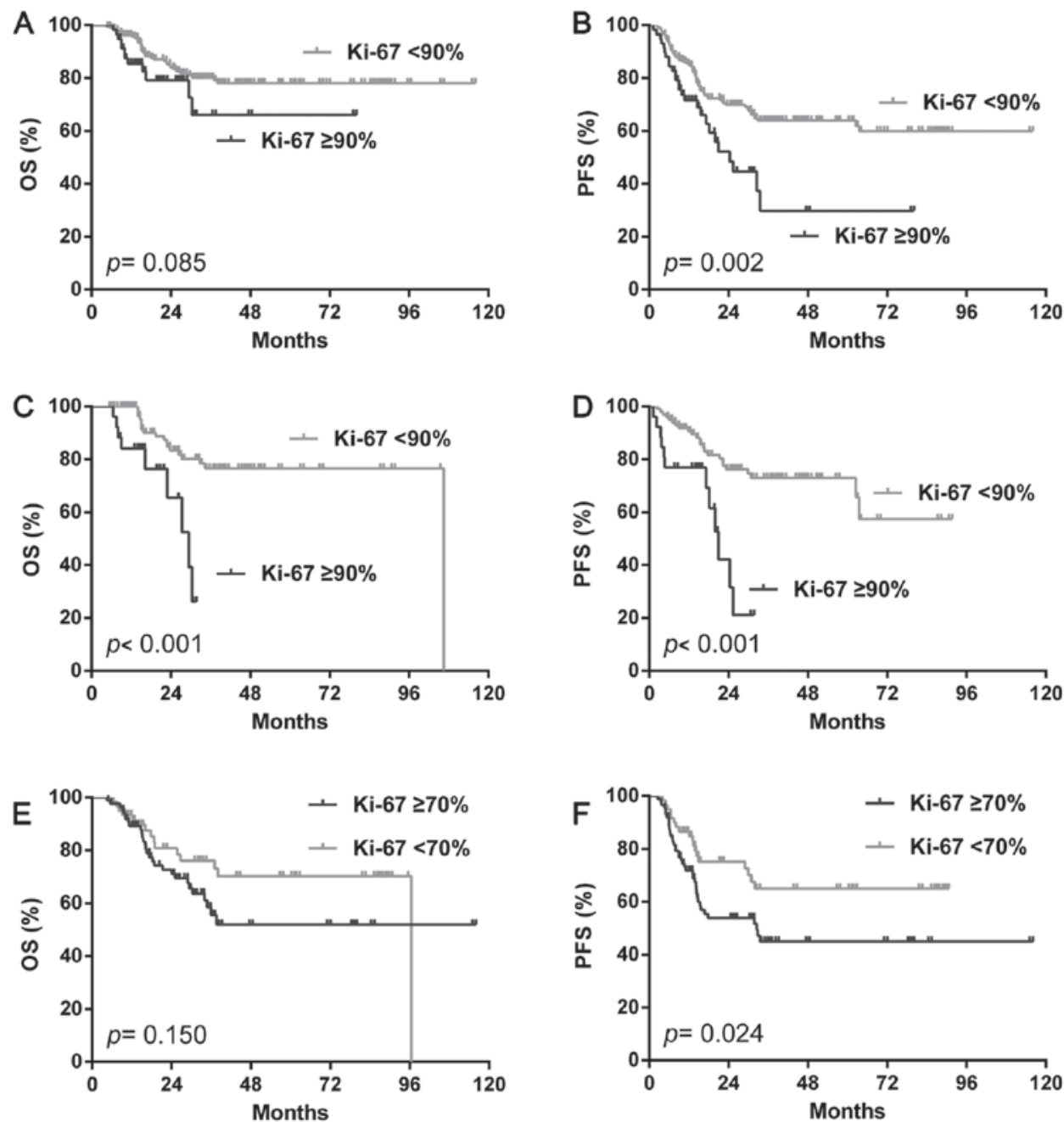

Figure 3. OS and PFS of patients with DLBCL of different Ki-67 index. (A) OS and (B) PFS with high and low Ki-67 (cut off: $90 \%$ ) index patients in total cohort. (C) OS and (D) PFS with high and low Ki-67 (cut off: 90\%) index patients in GCB-DLBCL cohort. (E) OS and (F) PFS with high and low Ki-67 (cut off: 70\%) index patients in NGC-DLBCL cohort. OS, overall survival; PFS, progression-free survival; DLBCL, diffuse large B-cell lymphoma; GCB, germinal center B-cell.
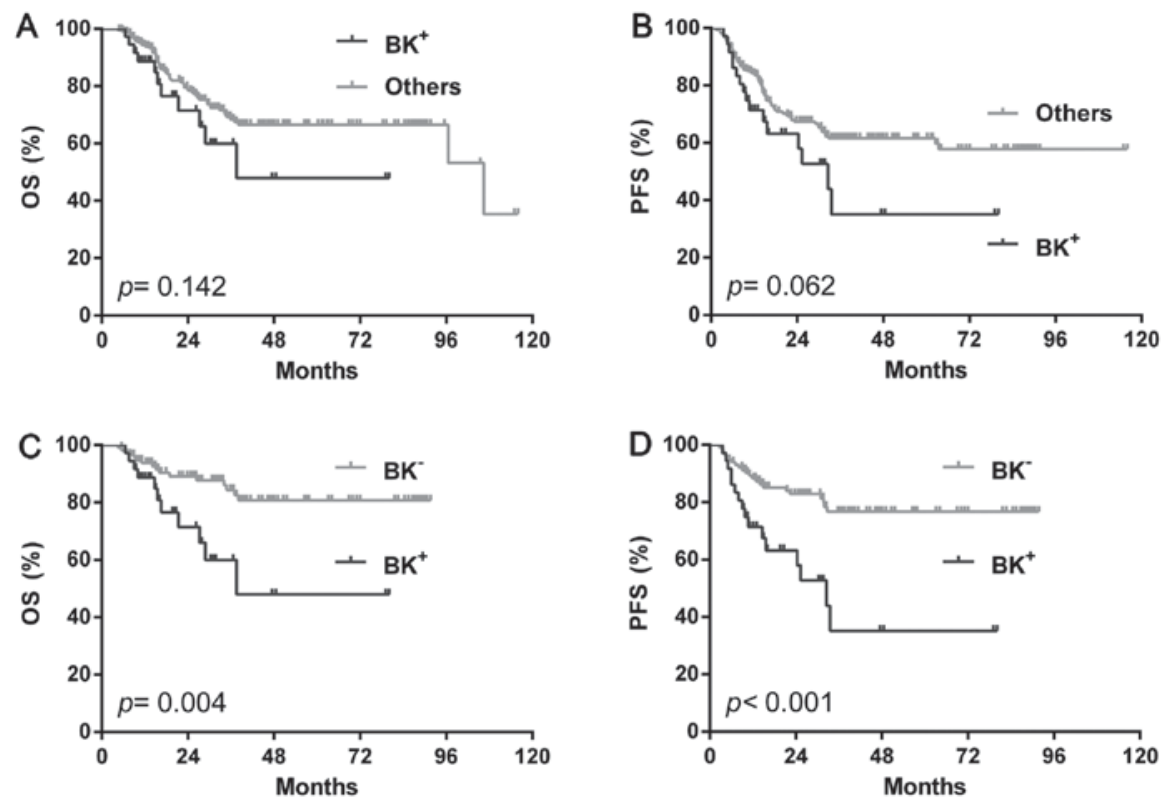

Figure 4. OS and PFS of patients with DLBCL of the BCL2 and Ki-67 index (BK) in total cohort. (A) OS and (B) PFS with coexpression of BCL2 and Ki-67 protein vs. rest of the patients in total cohort. (C) OS and (D) PFS with coexpression of BCL2 and Ki-67 protein vs. double negative of BCL2 and Ki-67 protein in total cohort. OS, overall survival; PFS, progression-free survival; DLBCL, diffuse large B-cell lymphoma. 

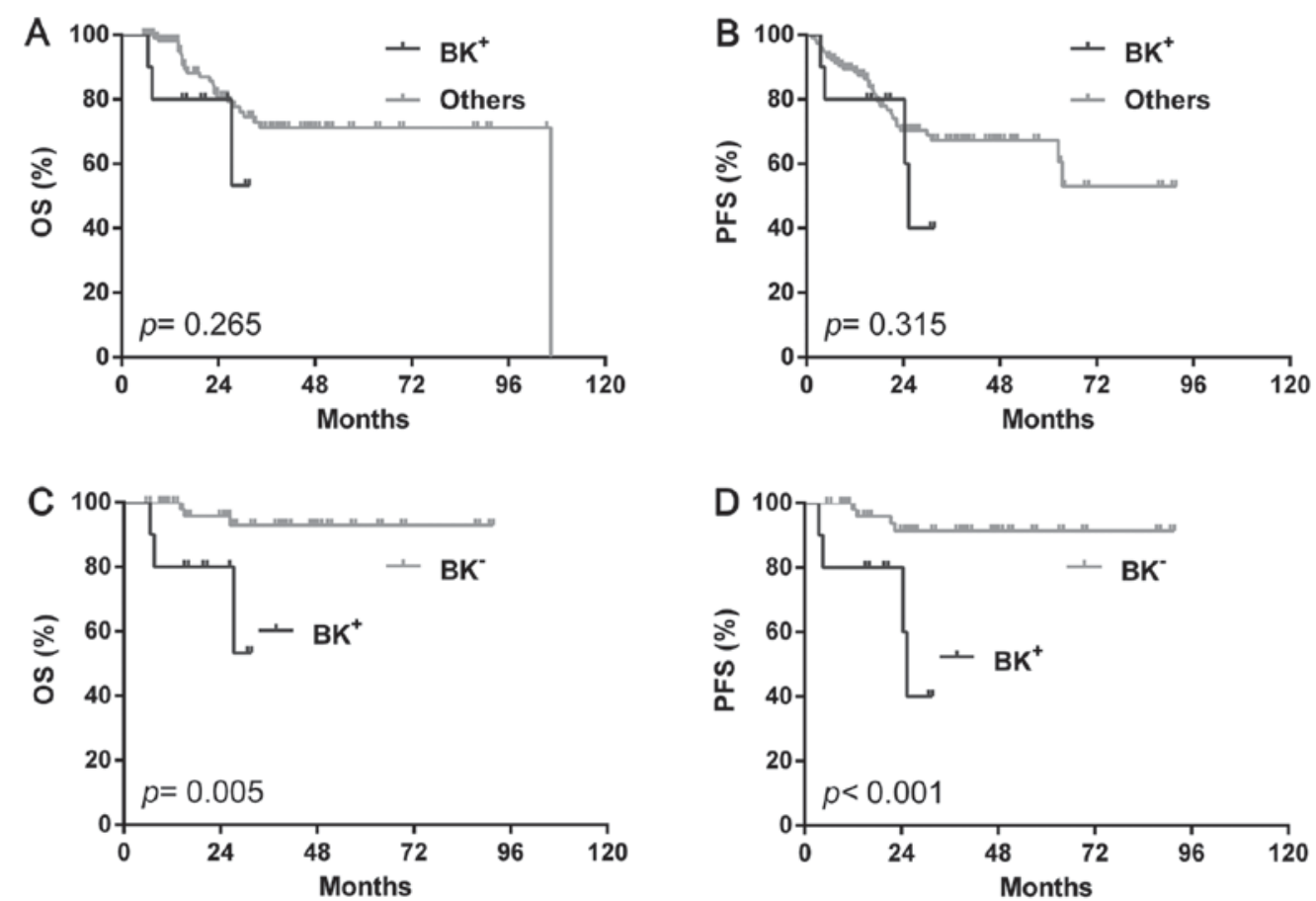

Figure 5. OS and PFS of patients with DLBCL of the BCL2 and Ki-67 index (BK) in GCB-DLBCL cohort. (A) OS and (B) PFS with coexpression of BCL2 and Ki-67 protein vs. rest of the patients in GCB-DLBCL cohort. (C) OS and (D) PFS with coexpression of BCL2 and Ki-67 protein vs. double negative of BCL2 and Ki-67 protein in GCB-DLBCL cohort. OS, overall survival; PFS, progression-free survival; DLBCL, diffuse large B-cell lymphoma.
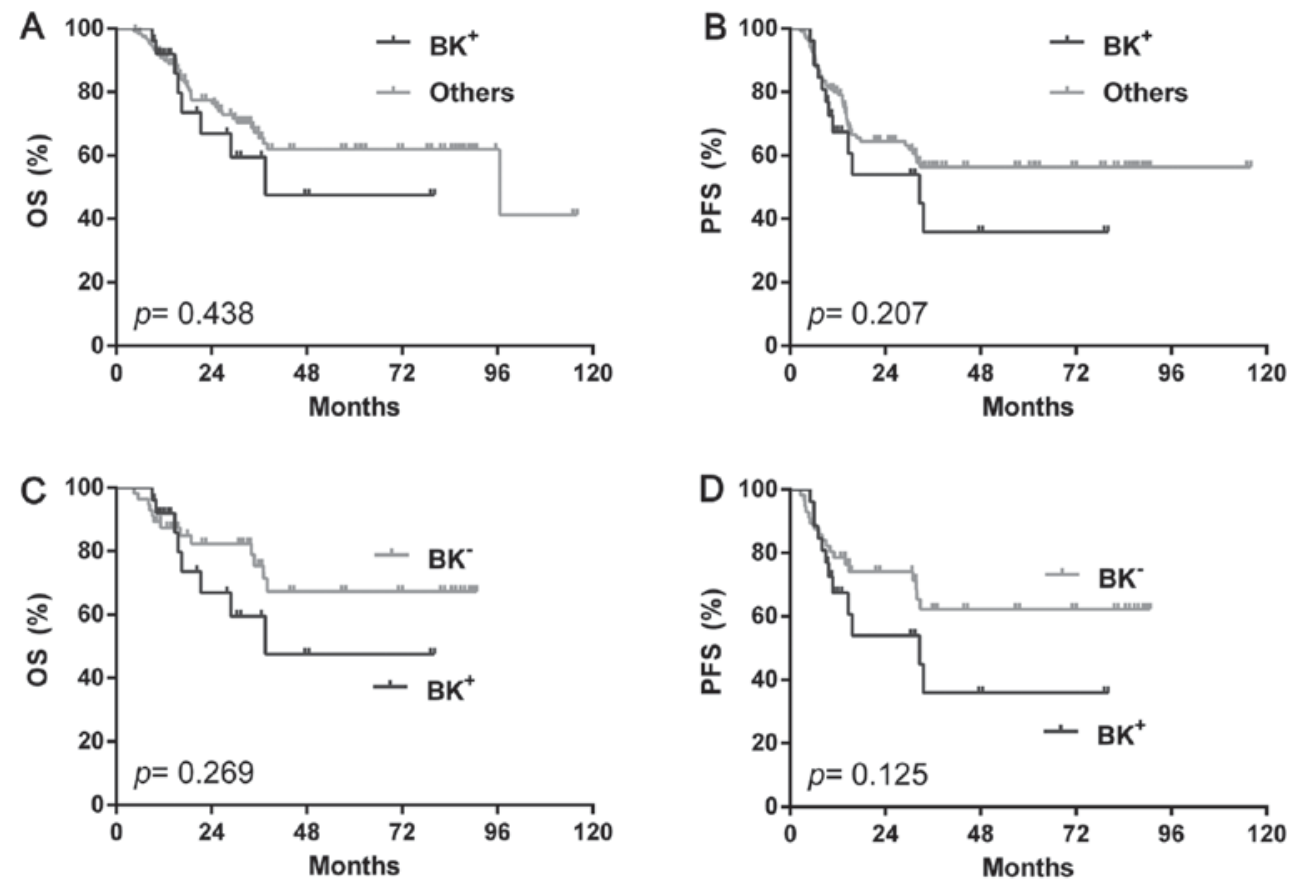

Figure 6. OS and PFS of patients with DLBCL of the BCL2 and Ki-67 index (BK) in NGC-DLBCL cohort. (A) OS and (B) PFS with coexpression of BCL2 and $\mathrm{Ki}-67$ protein vs. rest of the patients in NGC-DLBCL cohort. (C) OS and (D) PFS with coexpression of BCL2 and Ki-67 protein vs. double negative of BCL2 and Ki-67 protein in NGC-DLBCL cohort. OS, overall survival; PFS, progression-free survival; DLBCL, diffuse large B-cell lymphoma. NGC, non-germinal center B-cell.

Although most DLBCL patients are cured with 6-8 cycles of R-CHOP chemotherapy, about $10-15 \%$ ones have primary refractory disease and a further $20-30 \%$ relapse. There is an urgent need to improve outcome for these patients. In the precision medicine era, target $\mathrm{CD} 20$ alone might not be enough. Studies also suggest improvement in outcome on the use of rituximab with CHOP in ABC-DLBCL and the BCL2 negative subset of GCB-DLBCL. However, the BCL2 positive GCB-DLBCL has shown less improvement, and these cases may benefit from novel agents such as inhibitors of BCL2 
function (14). Targeted inhibition of BCL2 with its highly selective inhibitor ABT-199 recently emerged as a promising treatment strategy for some B-cell malignancies such as CLL and MCL (26,27). ABT-199 was proved potentially effective in BCL2 positive DLBCL (28). In GCB-DLBCL with BCL2 positive might benefit from ABT-199 or other inhibitors of BCL2 function. Besides, to inhibition of MYC expression via BRD4 inhibitor, such as JQ1, might indirectly be another way to target high Ki-67 proliferation DLBCL (29).

In conclusion, we have described a method for the combinatorial assessment of BCL2 and Ki-67 as measured by IHC. The BCL2/Ki-67 index was a highly effective predictor of patients outcome with DLBCL, especially in the GCB-DLBCL group. In multivariate analysis, $\mathrm{BK}^{+}$remained significantly prognostic factor of PFS in DLBCL. In the precision medicine era, targeting $\mathrm{BK}^{+}$therapies might be potentially promising ways to improve patients' outcome.

\section{References}

1. Moskowitz C: Diffuse large B cell lymphoma: How can we cure more patients in 2012? Best Pract Res Clin Haematol 25: 41-47, 2012.

2. Pileri SA, Agostinelli C, Sabattini E, Bacci F, Sagramoso C, Pileri A Jr, Falini B and Piccaluga PP: Lymphoma classification: The quiet after the storm. Semin Diagn Pathol 28: 113-123, 2011.

3. Abid MB, Nasim F, Anwar K and Pervez S: Diffuse large B cell lymphoma (DLBCL) in Pakistan: An emerging epidemic? Asian Pac J Cancer Prev 6: 531-534, 2005.

4. Song CG, Huang JJ, Li YJ, Xia Y, Wang Y, Bi XW, Jiang WQ, Huang HQ, Lin TY and Li ZM: Epstein-barr virus-positive diffuse large B-cell lymphoma in the elderly: A matched case-control analysis. PLoS One 10: e0133973, 2015.

5. Harris NL, Jaffe ES, Diebold J, Flandrin G, Muller-Hermelink HK and Vardiman J: Lymphoma classification-from controversy to consensus: The R.E.A.L. and WHO Classification of lymphoid neoplasms. Ann Oncol 11 (Suppl 1): S3-S10, 2000.

6. Coiffier B: Rituximab therapy in malignant lymphoma. Oncogene 26: 3603-3613, 2007.

7. Sehn LH, Berry B, Chhanabhai M, Fitzgerald C, Gill K, Hoskins P, Klasa R, Savage KJ, Shenkier T, Sutherland J, et al: The revised International Prognostic Index (R-IPI) is a better predictor of outcome than the standard IPI for patients with diffuse large B-cell lymphoma treated with R-CHOP. Blood 109: $1857-1861,2007$.

8. He X, Chen Z, Fu T, Jin X, Yu T, Liang Y, Zhao X and Huang L: $\mathrm{Ki}-67$ is a valuable prognostic predictor of lymphoma but its utility varies in lymphoma subtypes: Evidence from a systematic meta-analysis. BMC Cancer 14: 153, 2014.

9. Song MK, Chung JS, Lee JJ, Yang DH, Kim IS, Shin DH and Shin HJ: High Ki-67 expression in involved bone marrow predicts worse clinical outcome in diffuse large B cell lymphoma patients treated with R-CHOP therapy. Int J Hematol 101: 140-147, 2015.

10. Li ZM, Huang JJ, Xia Y, Zhu YJ, Zhao W, Wei WX, Jiang WQ, Lin TY, Huang HQ and Guan ZZ: High Ki-67 expression in diffuse large B-cell lymphoma patients with non-germinal center subtype indicates limited survival benefit from R-CHOP therapy. Eur J Haematol 88: 510-517, 2012.

11. Hasselblom S, Ridell B, Sigurdardottir M, Hansson U, Nilsson-Ehle $\mathrm{H}$ and Andersson PO: Low rather than high Ki-67 protein expression is an adverse prognostic factor in diffuse large B-cell lymphoma. Leuk Lymphoma 49: 1501-1509, 2008.

12. Jerkeman M, Anderson H, Dictor M, Kvaløy S, Akerman M and Cavallin-Ståhl E; Nordic Lymphoma Group study: Assessment of biological prognostic factors provides clinically relevant information in patients with diffuse large B-cell lymphoma-a Nordic Lymphoma Group study. Ann Hematol 83: 414-419, 2004.

13. Ali HR, Dawson SJ, Blows FM, Provenzano E, Leung S, Nielsen T, Pharoah PD and Caldas C: A Ki67/BCL2 index based on immunohistochemistry is highly prognostic in ER-positive breast cancer. J Pathol 226: 97-107, 2012.
14. Iqbal J, Meyer PN, Smith LM, Johnson NA, Vose JM, Greiner TC, Connors JM, Staudt LM, Rimsza L, Jaffe E, et al: BCL2 predicts survival in germinal center B-cell-like diffuse large B-cell lymphoma treated with CHOP-like therapy and rituximab. Clin Cancer Res 17: 7785-7795, 2011.

15. Iqbal J, Neppalli VT, Wright G, Dave BJ, Horsman DE, Rosenwald A, Lynch J, Hans CP, Weisenburger DD, Greiner TC, et al: BCL2 expression is a prognostic marker for the activated B-cell-like type of diffuse large B-cell lymphoma. J Clin Oncol 24: 961-968, 2006.

16. Pfreundschuh M, Ho AD, Cavallin-Stahl E, Wolf M, Pettengell R, Vasova I, Belch A, Walewski J, Zinzani PL, Mingrone W, et al: Prognostic significance of maximum tumour (bulk) diameter in young patients with good-prognosis diffuse large-B-cell lymphoma treated with CHOP-like chemotherapy with or without rituximab: An exploratory analysis of the MabThera International Trial Group (MInT) study. Lancet Oncol 9: 435-444, 2008.

17. Hans CP, Weisenburger DD, Greiner TC, Gascoyne RD, Delabie J, Ott G, Müller-Hermelink HK, Campo E, Braziel RM, Jaffe ES, et al: Confirmation of the molecular classification of diffuse large B-cell lymphoma by immunohistochemistry using a tissue microarray. Blood 103: 275-282, 2004.

18. Hu S, Xu-Monette ZY, Tzankov A, Green T, Wu L, Balasubramanyam A, Liu WM, Visco C, Li Y, Miranda RN, et al: MYC/BCL2 protein coexpression contributes to the inferior survival of activated B-cell subtype of diffuse large B-cell lymphoma and demonstrates high-risk gene expression signatures: A report from The International DLBCL Rituximab-CHOP Consortium Program. Blood 121: 4021-4031, 2013.

19. Johnson NA, Slack GW, Savage KJ, Connors JM, Ben-Neriah S, Rogic S, Scott DW, Tan KL, Steidl C, Sehn LH, et al: Concurrent expression of MYC and BCL2 in diffuse large B-cell lymphoma treated with rituximab plus cyclophosphamide, doxorubicin, vincristine, and prednisone. J Clin Oncol 30: 3452-3459, 2012.

20. Green TM, Young KH, Visco C, Xu-Monette ZY, Orazi A, Go RS, Nielsen O, Gadeberg OV, Mourits-Andersen T, Frederiksen M, et al: Immunohistochemical double-hit score is a strong predictor of outcome in patients with diffuse large B-cell lymphoma treated with rituximab plus cyclophosphamide, doxorubicin, vincristine, and prednisone. J Clin Oncol 30: 3460-3467, 2012.

21. Mationg-Kalaw E, Tan LH, Tay K, Lim ST, Tang T, Lee YY and Tan SY: Does the proliferation fraction help identify mature B cell lymphomas with double- and triple-hit translocations? Histopathology 61: 1214-1218, 2012.

22. Akyurek N, Uner A, Benekli M and Barista I: Prognostic significance of MYC, BCL2, and BCL6 rearrangements in patients with diffuse large B-cell lymphoma treated with cyclophosphamide, doxorubicin, vincristine, and prednisone plus rituximab. Cancer 118: 4173-4183, 2012.

23. Wilson KS, Sehn LH, Berry B, Chhanabhai M, Fitzgerald CA, Gill KK, Klasa R, Skinnider B, Sutherland J, Connors JM and Gascoyne RD: CHOP-R therapy overcomes the adverse prognostic influence of BCL-2 expression in diffuse large B-cell lymphoma. Leuk Lymphoma 48: 1102-1109, 2007.

24. Mounier N, Briere J, Gisselbrecht C, Emile JF, Lederlin P, Sebban C, Berger F, Bosly A, Morel P, Tilly H, et al: Rituximab plus CHOP (R-CHOP) overcomes bcl-2-associated resistance to chemotherapy in elderly patients with diffuse large B-cell lymphoma (DLBCL). Blood 101: 4279-4284, 2003.

25. Hanahan D and Weinberg RA: Hallmarks of cancer: The next generation. Cell 144: 646-674, 2011.

26. Montraveta A, Xargay-Torrent S, Rosich L, López-Guerra M, Roldán J, Rodríguez V, Lee-Vergés E, de Frías M, Campàs C, Campo E, et al: Bcl-2high mantle cell lymphoma cells are sensitized to acadesine with ABT-199. Oncotarget 6: 21159-21172, 2015.

27. Cervantes-Gomez F, Lamothe B, Woyach JA, Wierda WG, Keating MJ, Balakrishnan K and Gandhi V: Pharmacological and protein profiling suggests venetoclax (ABT-199) as optimal partner with ibrutinib in chronic lymphocytic Leukemia. Clin Cancer Res 21: 3705-3715, 2015.

28. Klanova M, Andera L, Brazina J, Svadlenka J, Benesova S, Soukup J, Prukova D, Vejmelkova D, Jaksa R, Helman K, et al: Targeting of BCL2 family proteins with ABT-199 and homoharringtonine reveals BCL2- and MCL1-Dependent subgroups of diffuse large B-cell lymphoma. Clin Cancer Res 22: 1138-1149, 2016.

29. Shao Q, Kannan A, Lin Z, Stack BC Jr, Suen JY and Gao L: BET protein inhibitor JQ1 attenuates Myc-amplified MCC tumor growth in vivo. Cancer Res 74: 7090-7102, 2014. 